\title{
Association between circulating 25-hydroxyvitamin D concentrations and hip replacement for osteoarthritis: a prospective cohort study
}

\author{
Sultana Monira Hussain ${ }^{1 *+} \mathbb{0}$, Yuanyuan Wang ${ }^{1 \dagger}$, Alicia K. Heath², Graham G. Giles ${ }^{1,3,4}$, Dallas R. English ${ }^{3,4}$,
} Darryl W. Eyles ${ }^{5,6}$, Elizabeth J. Williamson7 ${ }^{7}$ Stephen E. Graves ${ }^{8,9}$, Anita E. Wluka ${ }^{1}$ and Flavia M. Cicuttini ${ }^{1}$

\begin{abstract}
Background: To examine the association between circulating 25(OH)D concentrations and incidence of total hip replacement for osteoarthritis in a prospective cohort study.

Methods: This study examined a random sample of 2651 participants in the Melbourne Collaborative Cohort Study who had 25(OH)D concentrations measured from dried blood spots collected in 1990-1994. Participants who underwent total hip replacement for osteoarthritis between January 2001 and December 2018 were identified by linking the cohort records to the Australian Orthopaedic Association National Joint Replacement Registry. Cox proportional hazard regression was used to estimate hazard ratios (HR) and 95\% confidence intervals (Cl) of total hip replacement for osteoarthritis in relation to 25(OH)D concentrations, adjusted for confounders.

Results: Eighty-six men and eighty-seven women had a total hip replacement for osteoarthritis. Compared with men in the lowest (1st) quartile of $25(\mathrm{OH}) \mathrm{D}$ concentration, the HR for total hip replacement was $2.32(95 \% \mathrm{Cl} 1.05$, 5.13) for those in the 2 nd quartile, $2.77(95 \% \mathrm{Cl} 1.28,6.00)$ for those in the 3 rd quartile, and $1.73(95 \% \mathrm{Cl} 0.75,4.02)$ for those in the highest quartile of $25(\mathrm{OH}) \mathrm{D}$ concentrations ( $p$ for trend 0.02 ). There was little evidence of an association in women.

Conclusions: Higher circulating $25(\mathrm{OH})$ D concentrations were associated with an increased risk of total hip replacement for osteoarthritis in men but not in women. Although the underlying mechanism warrants further investigation, our findings highlight the need to determine the optimal levels of circulating $25(\mathrm{OH}) \mathrm{D}$ to reduce the risk of hip osteoarthritis.
\end{abstract}

*Correspondence: monira.hussain@monash.edu

'Sultana Monira Hussain and Yuanyuan Wang contributed equally to this work.

1 Department of Epidemiology and Preventive Medicine, School of Public Health and Preventive Medicine, Monash University, 553 St Kilda Road, Melbourne, VIC 3004, Australia

Full list of author information is available at the end of the article

\section{Background}

Hip osteoarthritis (OA) causes pain and disability and is a common musculoskeletal condition that affects millions of people worldwide. The lifetime risk of symptomatic hip OA is $18.5 \%$ for men and $28.6 \%$ for women [1]. There are no effective treatments for hip OA that alter disease process; as a result the prevalence and burden of disease due to hip OA are increasing. Costly total hip replacements are used to treat symptomatic end-stage hip OA, original author(s) and the source, provide a link to the Creative Commons licence, and indicate if changes were made. The images or other third party material in this article are included in the article's Creative Commons licence, unless indicated otherwise in a credit line to the material. If material is not included in the article's Creative Commons licence and your intended use is not permitted by statutory regulation or exceeds the permitted use, you will need to obtain permission directly from the copyright holder. To view a copy of this licence, visit http://creativecommons.org/licenses/by/4.0/. The Creative Commons Public Domain Dedication waiver (http://creativecommons.org/publicdomain/zero/1.0/) applies to the data made available in this article, unless otherwise stated in a credit line to the data. 
but 7 to $23 \%$ of patients experience ongoing pain despite technically successful surgery [2]. Therefore the strategy for reducing the burden of hip OA lies in shifting the management paradigm from palliation to disease prevention and reduction of disease progression.

As the hip is a ball and socket joint, it is susceptible to altered hip bone shape and joint congruency, which are important risk factors for the development and progression of hip OA [3]. Vitamin D is critical in bone mineralization, remodelling, and maintenance and thus is capable of changing bone shape [4]. Serum or plasma 25 -hydroxyvitamin D [25(OH)D] concentration is considered the best indicator of vitamin D status [5]. Previous studies have examined whether circulating $25(\mathrm{OH})$ $\mathrm{D}$ concentrations are associated with hip OA in populations at risk of osteoporosis $[6,7]$ or community-based populations [8-10]. Two studies reported that low serum levels of $25(\mathrm{OH}) \mathrm{D}$ were associated with increased prevalence and incidence of radiographic hip OA among men and women aged $\geq 65$ years (mean age 73.5 years, standard deviation 5.8 years) $[6,7]$. However, there is uncertainty regarding the generalizability of these results. In the Study of Osteoporotic Fractures, women who had low incidence of fracture were excluded $[6,11]$, and in the Osteoporotic Fractures in Men Study, 17\% of participants reported a fracture in the year prior to recruitment $[7,12]$, indicating the presence of selection bias towards high risk of fracture in both studies. The three community-based cohort studies not primarily aimed at examining osteoporosis [8-10] are summarized in Table 1. One Finnish study of 805 participants found no association between circulating $25(\mathrm{OH}) \mathrm{D}$ concentrations and the incidence of hip OA, based on 40 cases of hip OA [10]. In contrast, another Finnish study of 5274 participants showed a trend of increased risk of hip OA associated with increasing circulating $25(\mathrm{OH}) \mathrm{D}$ concentrations, but this study was based on only 45 cases of hip OA [9]. In an Australian study of 9135 participants, we found that higher concentrations of circulating $25(\mathrm{OH}) \mathrm{D}$ were associated with increased risk of hip replacement for severe OA in men but not in women [8]. We used a robust definition of hip OA, i.e. hip replacement for OA, which in the context of the Australian healthcare system is a valid measure of severe hip OA, as all Australian citizens and permanent residents have access to quality health care services under Australia's publicly funded universal health insurance system (Medicare). Furthermore, our study had a large number of joint replacements, increasing the power to show potential associations [8].

Given the major focus on targeting vitamin D for the prevention of osteoporosis, understanding the effect of vitamin D on the risk of hip OA will be important to inform public health recommendations. As there is uncertainty regarding the association between circulating 25(OH)D concentrations and hip OA, we used a different well-established cohort study, with participants recruited from the community independent of any musculoskeletal disease, and long-term follow-up with enriched data prospectively collected [13], to investigate whether circulating $25(\mathrm{OH}) \mathrm{D}$ concentrations are associated with the incidence of total hip replacement for severe OA.

\section{Methods \\ Participants}

The Melbourne Collaborative Cohort Study (MCCS) is a prospective cohort study of 41,513 participants aged 27-75 years, recruited via the electoral roll, advertisements and community announcements in local media between 1990 and 1994, aimed at investigating the roles of diet and lifestyle in cancer and other non-communicable diseases $[13,14]$. The study protocol was approved by the Cancer Council Victoria Human Research Ethics Committee (IEC No. 9001). Participants gave written informed consent to participate and for the investigators to obtain access to their medical records.

A case-cohort study nested within the MCCS was set up to investigate $25(\mathrm{OH}) \mathrm{D}$ in relation to breast, prostate, and colorectal cancers, diabetes, and mortality. Eligibility for the case-cohort study was restricted to participants who had dried blood spot samples available and no diagnosis of cancer prior to recruitment (n eligible $=29,205$ ). As part of the case-cohort study, a sex-stratified random sample of 2996 eligible participants was selected as the "subcohort". The current investigation involves this random sample of subcohort participants. All methods were carried out in accordance with relevant guidelines and regulations.

\section{Identification of hip replacement}

Participants with a primary total hip replacement were identified from the Australian Orthopaedic Association National Joint Replacement Registry (AOA NJRR). The Registry began data collection in September 1999 and implementation was introduced in a staged fashion in each of the Australian states and territories. Victoria commenced data collection in January 2001 and the AOA NJRR has collected national data on joint replacement procedures performed in Australia since 2002 [15]. The Registry has detailed information on the joint replacement prostheses, patient demographics, the reason for joint replacement, whether it is a primary joint replacement or a revision and the type of revision. Data are collected from both public and private hospitals and this is validated using a sequential multi-level matching process against State and Territory Health Department unit record data [15]. Following the validation process 


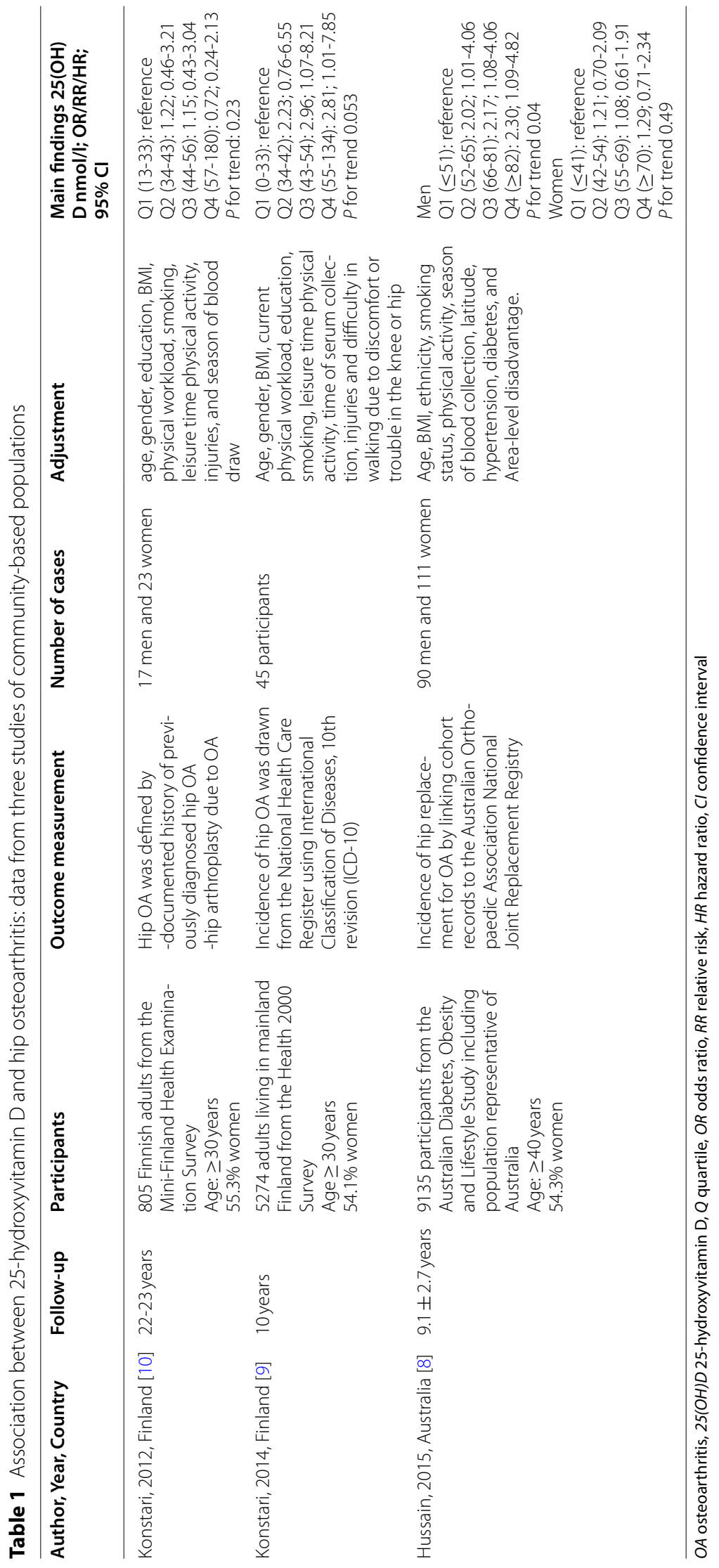


and retrieval of unreported records, the Registry collects an almost complete set of data relating to hip and knee replacements in Australia [15]. Identifying information for MCCS participants, including first name, last name, date of birth, and sex, was provided to the staff at the AOA NJRR in order to identify MCCS participants who had undergone a joint replacement between 1 January 2001 and 31 December 2018. The matching was performed on these data provided using the Freely Extensible Biomedical Record Linkage (Febrl) system. Exact matches were identified and probabilistic matches were reviewed. The data linkage study protocol was approved by the Human Research Ethics Committees of Cancer Council Victoria (HREC 0601), and Monash University (2006000608).

\section{Demographic, lifestyle factors, medical history, and anthropometrics}

At recruitment, data on demographic (sex, date of birth, country of birth) and lifestyle factors (physical activity, smoking status), Socio-Economic Indexes For Areas (SEIFA) index of relative disadvantage in quintile groups, and medical history (diabetes and hypertension) were collected using questionnaires in face-to-face interviews [13]. Physical activity was assessed by three separate questions obtained from the Risk Factor Prevalence Study conducted by the National Heart Foundation and Australian Institute of Health regarding frequency of non-occupational vigorous and moderate physical activity, and walking $[16,17]$. Participants were categorised as whether or not participating in vigorous activity in line with values published in the Compendium of Physical Activities [18]. Height and weight were measured according to written protocols based on standard procedures, and body mass index (BMI) was calculated [13]. Data on self-reported knee and hip replacement were collected at the second wave of active follow-up (2003-2007).

\section{Circulating 25(OH)D measurement}

Blood samples were collected, and for participants recruited from the second year of recruitment onwards (i.e. for approximately $75 \%$ of participants), whole blood was spotted onto Whatman 903 paper. Spots were air dried and then stored in the dark. Circulating $25(\mathrm{OH})$ $\mathrm{D}$ concentrations were measured from dried blood spots using liquid chromatography-tandem mass spectrometry (LC-MS/MS) as previously described $[19,20]$. The laboratory uses National Institute of Standards and Technology (NIST) Vitamin D Standard Reference Materials and participates in the Vitamin D External Quality Assessment Scheme (DEQAS). It has been shown that measurement of $25(\mathrm{OH}) \mathrm{D}$ in dried blood spots is a valid and reliable alternative to conventional serum or plasma measurement [19]. Importantly, a simple calibration model has been developed to convert dried blood spot measurements to equivalent plasma concentrations, facilitating comparisons against clinical reference ranges and with studies using sera or plasma samples [19]. Measured 25(OH)D concentrations in dried blood spots were corrected for batch effects and seasonal variation and converted to plasma-equivalent concentrations as previously described [21]. All results presented are for batch- and season-adjusted plasma-equivalent 25(OH)D concentrations.

\section{Statistical analysis}

Participants were excluded if $25(\mathrm{OH}) \mathrm{D}$ measurements were not performed $(n=10)$; they died or left Australia before January 2002; they reported at the second wave of follow-up (2003-2007) having had a joint replacement prior to 1 January 2001; left Australia before the date of a primary joint replacement; their first recorded procedure in the AOA NJRR was a revision joint replacement $(n=335)$ (Fig. 1).

Characteristics and the number of hip replacements in participants who were included in the current study and all other MCCS participants were compared. Characteristics of study participants were tabulated based on sex and hip replacement for OA. Cox proportional hazards regression analyses were used to estimate hazard ratios (HRs) and 95\% confidence intervals (CIs) for hip replacement due to $\mathrm{OA}$ in relation to $25(\mathrm{OH}) \mathrm{D}$ concentrations, with age as the time scale. Follow-up for total hip replacement for OA (i.e. calculation of person-time) began on 1 January 2001, and ended at the date of first total hip replacement for OA or date of censoring. Participants were censored at the date of first total hip replacement performed for indications other than OA including hip fracture, avascular necrosis; the date of first total knee replacement; the date of death; the date the participant left Australia; or end of follow-up (i.e. 31 December 2018, the date that ascertainment of joint replacement by the AOA NJRR was complete); whichever came first. The linear association between circulating $25(\mathrm{OH}) \mathrm{D}$ concentrations and total hip replacement for OA was examined by fitting $25(\mathrm{OH}) \mathrm{D}$ as a continuous variable, and reported per $25 \mathrm{nmol} / \mathrm{L}$ increment. Circulating $25(\mathrm{OH}) \mathrm{D}$ concentrations were also categorized into sex-specific quartiles. The lowest quartile was used as the referent category. For tests of linear trend, participants were assigned the median value in each quartile, and the corresponding variable was modelled continuously.

To test whether the association between $25(\mathrm{OH}) \mathrm{D}$ concentrations and total hip replacement for OA was modified by sex, interactions were fitted and tested using the likelihood ratio test. Since there was evidence for an 


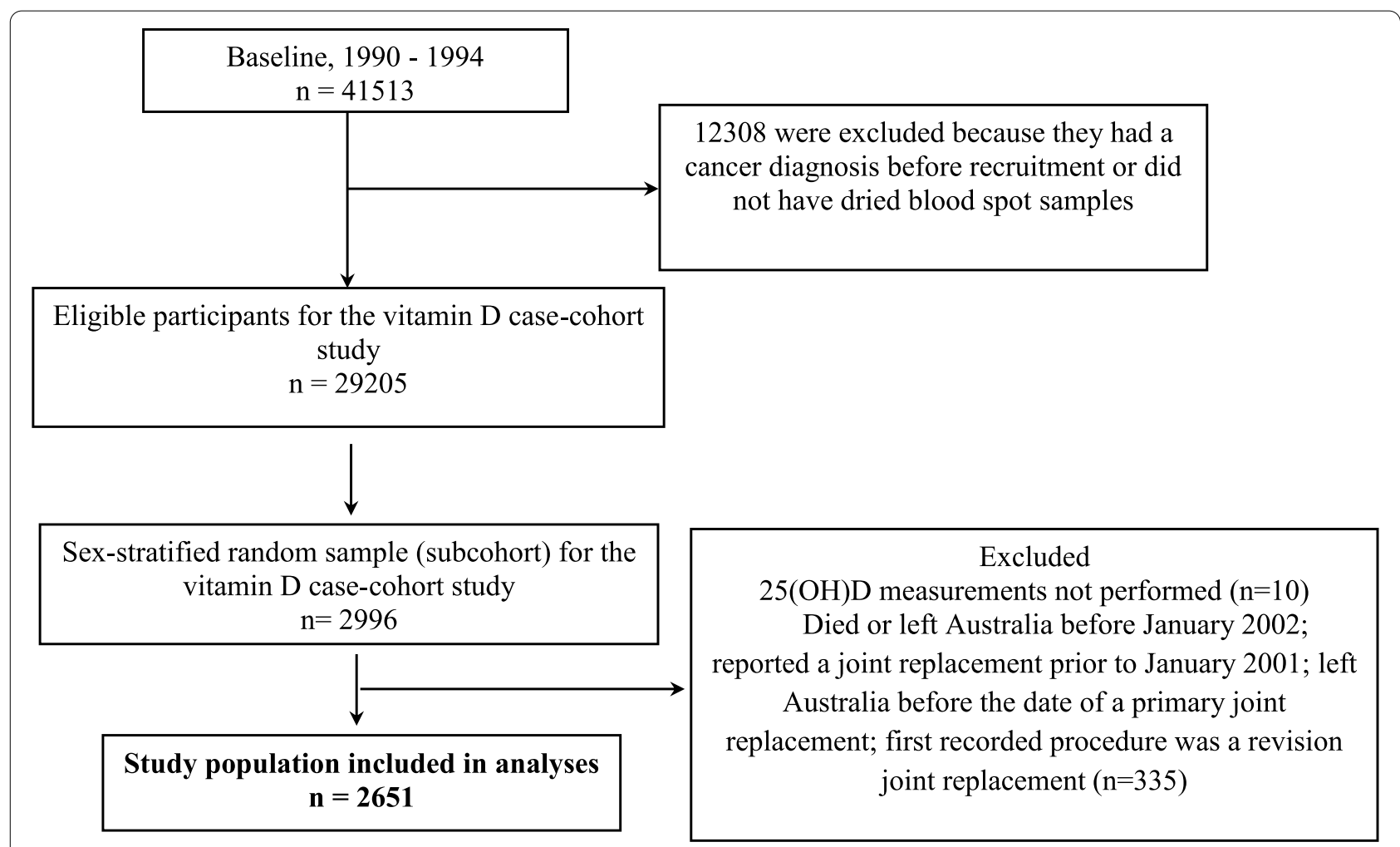

Fig. 1 Flowchart of Melbourne Collaborative Cohort Study participants included in the analyses

interaction $(p=0.06)$, all analyses were performed for men and women separately, and adjusted for BMI $\left(\mathrm{kg} / \mathrm{m}^{2}\right.$, modelled continuously), vigorous physical activity (any vs no), smoking status (former/current vs never), country of birth (Australia/United Kingdom vs Italy/Greece), socioeconomic disadvantage (quintiles of Socio-Economic Indexes for Areas [SEIFA], most deprived [quintiles 1-3] vs least deprived [quintiles 4-5]), and co-morbidities (yes vs no): diabetes and hypertension. All statistical analyses were performed using Stata 15.0 SE (StataCorp LP., College Station, TX, USA).

\section{Results}

Participants of the current study were younger $(53.7 \pm 8.7$ vs. $55.1 \pm 8.6$ years $)$, more likely to be men $(54.6 \%$ vs $39.1 \%)$, to be born in Australia and UK (84.7\% vs $75.3 \%)$, to participate in vigorous physical activity $(25.9 \%$ vs $21.1 \%)$, to be former/current smokers $(54.0 \%$ vs $41.5 \%)$, to be in the upper two (least disadvantaged) quintiles of SEIFA (53.6\% vs $45.6 \%)$, and less likely to have hypertension $(17.7 \%$ vs $21.5 \%)$ and diabetes ( $2.5 \%$ vs. $3.5 \%)$, compared with MCCS participants who were not included in the analysis. There was no significant difference in prevalence of total hip replacement for OA between the two groups (6.5\% vs. $5.7 \%)$.
One hundred and seventy three participants (86 men and 87 women) had a total hip replacement for OA from January 2001 until December 2018, a mean follow-up of 15.7 (SD 4.6) years. The characteristics of the participants are presented in Table 2. Compared with men without a total hip replacement, men with a total hip replacement were less likely to be in the lowest $25(\mathrm{OH}) \mathrm{D}$ quartile and more likely to be in the 3rd $25(\mathrm{OH}) \mathrm{D}$ quartile, more likely to be least deprived and participate in vigorous physical activity, and less likely to be current/former smokers. Women having a hip replacement did not noticeably differ with respect to levels of $25(\mathrm{OH}) \mathrm{D}$ or other variables with those who did not have a hip replacement.

In men, the HR for total hip replacement for OA was 1.23 (95\% CI $0.95-1.60)$ per $25 \mathrm{nmol} / \mathrm{L}$ increment in 25(OH)D concentration after adjusting for BMI, vigorous physical activity, smoking status, country of birth, and SEIFA (Table 3). Compared with men in the lowest (1st) quartile of $25(\mathrm{OH}) \mathrm{D}$ concentration, the HR for total hip replacement for OA was 2.06 (95\% CI 1.02, 4.13) for those in the 2nd quartile, 2.40 (95\% CI 1.21, 4.75) for those in the 3rd quartile, and 1.57 (95\% CI $0.75,3.29$ ) for those in the highest quartile of $25(\mathrm{OH}) \mathrm{D}$ concentrations ( $p$ for trend 0.04). Additional adjustment for co-morbidities (diabetes and hypertension) did not change the 
Table 2 Characteristics of study participants at recruitment

\begin{tabular}{|c|c|c|c|c|}
\hline & \multicolumn{2}{|l|}{ Men } & \multicolumn{2}{|l|}{ Women } \\
\hline & \multicolumn{2}{|c|}{ Total hip replacement for $\mathrm{OA}$} & \multicolumn{2}{|c|}{ Total hip replacement for $\mathrm{OA}$} \\
\hline & No & Yes & No & Yes \\
\hline Number of participants & 1379 & 86 & 1099 & 87 \\
\hline 25(OH)D (nmol/L), median (IQR) & $54.5(42.7-69.0)$ & $57.0(47.3-66.4)$ & $42.8(34.7-52.7)$ & $44.6(34.5-53.3)$ \\
\hline \multicolumn{5}{|l|}{ 25(OH)D Quartile, n (\%) } \\
\hline $1(\mathrm{M}<43.00 ; \mathrm{F}<34.80 \mathrm{nmol} / \mathrm{L})$ & $354(25.7)$ & $12(13.9)$ & $279(25.3)$ & $23(26.4)$ \\
\hline 2 (M 43.00-<54.85; F 34.80-<42.92 nmol/L) & $346(25.1)$ & $24(27.9)$ & $278(25.3)$ & $19(21.8)$ \\
\hline 3 (M 54.85-<69.22; F 42.92-<53.04 nmol/L) & $337(24.4)$ & $31(36.1)$ & $272(24.8)$ & $23(26.4)$ \\
\hline $4(\mathrm{M} \geq 69.22 ; F \geq 53.04 \mathrm{nmol} / \mathrm{L})$ & $342(24.8)$ & $19(22.1)$ & $270(24.6)$ & $22(25.3)$ \\
\hline Age (years), mean (SD) & $53.5(9.0)$ & $55.4(8.2)$ & $53.3(8.6)$ & $56.6(8.1)$ \\
\hline Body mass index $\left(\mathrm{kg} / \mathrm{m}^{2}\right)$, mean (SD) & $26.8(3.5)$ & $28.1(3.2)$ & $26.1(5.0)$ & $26.8(4.4)$ \\
\hline \multicolumn{5}{|l|}{ Country of birth, n (\%) } \\
\hline Australia/United Kingdom & $1129(81.9)$ & $73(84.9)$ & $948(86.3)$ & $79(90.8)$ \\
\hline Italy/Greece & $250(18.1)$ & $13(15.1)$ & $151(13.7)$ & $8(9.2)$ \\
\hline \multicolumn{5}{|l|}{ Socioeconomic status (SEIFA), n (\%) } \\
\hline Most deprived (quintiles 1-3) & $678(49.4)$ & $37(43.0)$ & $475(43.3)$ & $38(43.7)$ \\
\hline Least deprived (quintiles 4-5) & $694(50.6)$ & $49(57.0)$ & $621(56.7)$ & $49(56.3)$ \\
\hline Vigorous physical activity, n (\%) & $360(26.1)$ & $31(36.1)$ & $269(24.5)$ & $22(25.3)$ \\
\hline Smoking (former/current), n (\%) & $766(55.6)$ & $41(47.7)$ & $355(32.3)$ & $34(39.1)$ \\
\hline Diabetes, n (\%) & $58(4.9)$ & $2(2.8)$ & $22(2.3)$ & $1(1.3)$ \\
\hline Hypertension, n (\%) & $257(21.5)$ & $16(22.5)$ & $212(21.8)$ & $20(25.6)$ \\
\hline
\end{tabular}

$O A$ osteoarthritis, 25(OH)D 25-hydroxyvitamin D, IQR interquartile range, $M$ male, $F$ female, SD standard deviation, SEIFA Socio-Economic Indexes for Areas

Table 3 Hazard ratios of total hip replacement for osteoarthritis in relation to circulating 25-hydroxyvitamin D concentrations

\begin{tabular}{|c|c|c|}
\hline & Model $1^{\mathrm{a}}, \mathrm{HR}(95 \% \mathrm{Cl})$ & Model $2^{\mathrm{b}}, \mathrm{HR}(95 \% \mathrm{Cl})$ \\
\hline \multicolumn{3}{|l|}{ Men } \\
\hline 25(OH)D (per 25 nmol/L increment) & $1.23(0.95-1.60) p=0.12$ & $1.26(0.95-1.67) p=0.11$ \\
\hline \multicolumn{3}{|l|}{ 25(OH)D Quartiles } \\
\hline $1(<43.00 \mathrm{nmol} / \mathrm{L})$ & Reference & Reference \\
\hline 2 (43.00 to <54.85 nmol/L) & $2.06(1.02-4.13)$ & $2.32(1.05-5.13)$ \\
\hline $3(54.85$ to $<69.22 \mathrm{nmol} / \mathrm{L})$ & $2.40(1.21-4.75)$ & $2.77(1.28-6.00)$ \\
\hline $4(\geq 69.22 \mathrm{nmol} / \mathrm{L})$ & $1.57(0.75-3.29)$ & $1.73(0.75-4.02)$ \\
\hline Pfor trend & 0.04 & 0.02 \\
\hline \multicolumn{3}{|l|}{ Women } \\
\hline 25(OH)D (per 25 nmol/L increment) & $0.97(0.64-1.47) p=0.90$ & $0.94(0.60-1.47) p=0.78$ \\
\hline \multicolumn{3}{|l|}{ 25(OH)D Quartiles } \\
\hline $1(<34.8 \mathrm{nmol} / \mathrm{L})$ & Reference & Reference \\
\hline $2(34.8$ to $<42.92 \mathrm{nmol} / \mathrm{L})$ & $0.74(0.40-1.37)$ & $0.60(0.32-1.16)$ \\
\hline 3 (42.92 to <53.04 nmol/L) & $0.92(0.51-1.66)$ & $0.79(0.43-1.47)$ \\
\hline $4(\geq 53.04 \mathrm{nmol} / \mathrm{L})$ & $0.86(0.47-1.57)$ & $0.77(0.41-1.44)$ \\
\hline Pfortrend & 0.93 & 0.34 \\
\hline
\end{tabular}

25(OH)D 25-hydroxyvitamin D, HR hazard ratio, Cl confidence interval

a adjusted for BMI, vigorous physical activity, smoking status, country of birth, and SEIFA

${ }^{b}$ adjusted for BMI, vigorous physical activity, smoking status, country of birth, SEIFA, and co-morbidities (diabetes and hypertension) 
results. In women, there was little evidence of an association (Table 3).

\section{Discussion}

In this population-based cohort of middle-aged and older individuals, higher circulating 25(OH)D concentrations were associated with an increased risk of having a total hip replacement for OA in men but not in women, confirming our previous findings from an independent community-based cohort study [8].

In the Australian Diabetes, Obesity and Lifestyle Study of 9135 participants followed up for 9.1 (SD 2.7) years, we found an increased risk of having a hip replacement for OA with higher serum 25(OH)D concentrations in men but not women [8]. The current study examining an independent cohort, the MCCS, with a follow-up of 15.7 (SD 4.6) years, observed similar findings when hip OA was defined as hip replacement acquired from linking the cohort to NJRR. These linkage data are validated [22] and nearly complete (>99\%) regarding joint replacements in Australia [15]. Our findings from the two Australian cohort studies are supported by findings from the Finland Health 2000 study which showed that higher concentrations of $25(\mathrm{OH}) \mathrm{D}$ were associated with an increased risk of developing hip OA [9]. However the Finnish study had only 45 cases of incident hip OA so was underpowered to examine sex differences [9].

The mechanism for the association between higher $25(\mathrm{OH}) \mathrm{D}$ concentrations and increased risk of hip replacement for OA is not clear. Vitamin D plays an important role in bone mineralization, remodelling and maintenance, and greater serum 25(OH)D concentrations are associated with increased bone mineral density $[23,24]$. The effect of vitamin $D$ on anabolic bone changes might lead to subchondral bone sclerosis and altered hip bone shape. There is increasing evidence that hip bone shape is modifiable and subtle changes in hip bone shape increase the risk of hip OA [3, 25], and that increased bone mineral density is a risk factor for hip OA [26]. The sex difference that we observed for the association between circulating $25(\mathrm{OH}) \mathrm{D}$ concentrations and severe hip OA may be mediated through circulating levels of testosterone and estrogen, since these hormones play a role in regulating vitamin D and calcium homeostasis [27]. Similarly, vitamin D is known to affect androgen synthesis in testicular cells in men [28], and possibly ovarian androgens and testosterone levels in women [29]. Other studies have also reported sex-dependent skeletal effects of vitamin D [30]. We have shown a link between sex steroid hormones and total hip replacement for OA $[22,31]$. Sex differences in adiposity and body fat distribution might be another possible explanation. In our study, the HR for the association between $25(\mathrm{OH}) \mathrm{D}$ and
THR was lower in the highest quartile compared with the HRs of the middle two quartiles, which is comparable to the biphasic relationship seen between $25(\mathrm{OH})$ $\mathrm{D}$ and chronic diseases such as cardiovascular disease [32], schizophrenia [33], and mortality [34]. However, any potential biphasic relationship between $25(\mathrm{OH}) \mathrm{D}$ and THR, if exists, needs to be interpreted with caution given the small numbers of observations of THRs in each of the $25(\mathrm{OH}) \mathrm{D}$ quartiles in our study. It might mean that genetic and environmental factors relating to $25(\mathrm{OH}) \mathrm{D}$ play a role in OA pathogenesis as has been seen in case of bone health [35].

This study has limitations. Although circulating 25(OH)D concentrations were measured for a random sample of MCCS participants, there were some differences between participants included in this study and the rest of MCCS participants. However, it is unlikely that the selection of participants for the current study would affect the relationship between $25(\mathrm{OH}) \mathrm{D}$ and risk of total hip replacement for OA. Whilst participants with $25(\mathrm{OH}) \mathrm{D}$ measured had better health and higher socioeconomic position compared with those without measurements, the risks of hip replacement were similar in the two groups. Circulating 25(OH)D concentrations were measured at a single time point (i.e. MCCS recruitment). There is good intra-individual consistency in $25(\mathrm{OH}) \mathrm{D}$ concentrations measured several years apart, thus a single measurement is a reasonable measure of long-term vitamin D status [36-38]. Furthermore, in middle-aged Caucasian adults the main determinants of circulating $25(\mathrm{OH}) \mathrm{D}$ concentration are sex, age, obesity, latitude, season of blood collection, physical activity, and sun exposure $[39,40]$. Our study includes community-based people of European descent, living in a similar latitude (all living in Melbourne); we have performed sex-specific analysis, adjusted for age, BMI, physical activity; and measurements of $25(\mathrm{OH}) \mathrm{D}$ were corrected for season of blood collection. Thus any misclassification associated with single time measurement of $25(\mathrm{OH})$ $\mathrm{D}$ and total hip replacement for OA is likely to be nondifferential in nature. We could not control for occupational activity, since the MCCS did not have detailed information such as heavy lifting and climbing which are established risk factors for hip OA. We defined hip OA based on joint replacement which reflects end-stage joint disease, and thus less severe OA was not captured. It is possible that there is residual or unmeasured confounding, for example activities that might influence hip injury. We did not have accurate hip replacement data prior to 2001. It is possible that hip replacement occurring before 2001 might represent more rapidly progressive disease, yet we were only able to assess hip replacement for OA occurring after this time and cases in the first few years 
of follow-up were missed, this would have resulted in non-differential misclassification. Although it has been suggested that people who uses painkillers i.e. paracetamol, non-steroidal anti-inflammatory drugs (NSAIDs) and acetylsalicylic acid might have lower levels of vitamin D [41], the Danish Osteoporosis Prevention Study could not identify any difference in circulating levels of 25(OH)D between participants who were using pain killers and those who were not using pain killers (24.3(11.4) $\mathrm{ng} / \mathrm{ml}$ vs $25.2(12.3) \mathrm{ng} / \mathrm{ml} ; p=0.34)$ [42]. Furthermore, if pain killers were an explanatory factor in this study, we would have found more THR in those who had lower levels of circulating $25(\mathrm{OH}) \mathrm{D}$ which was not the case. Data on vitamin D supplementation were lacking. However, at the time of MCCS recruitment (1990-1994), supplement use in Australia was uncommon (16\% of MCCS participants reported using multivitamins at baseline), and this is unlikely to fully explain the observed association. Screening for vitamin D deficiency and vitamin D supplement use have increased since the early 2000s [43]. However, fluctuations in $25(\mathrm{OH}) \mathrm{D}$ measurements with differences between participants along time cannot be ruled out. Strengths of our study include its prospective cohort study design, validated and reliable measurement of circulating 25(OH)D concentrations [19], adjustment for important confounders, and the validation and completeness of AOA NJRR data on hip replacement for OA.

Internationally there is a major focus on targeting vitamin $\mathrm{D}$ deficiency in order to reduce the burden of osteoporotic fractures. However, the ideal concentration of $25(\mathrm{OH}) \mathrm{D}$ is still debated since some experts suggest concentrations less than $50 \mathrm{nmol} / \mathrm{L}$ are "insufficient" while others consider less than $75 \mathrm{nmol} / \mathrm{L}$ as "insufficient" [44-46]. There is increasing evidence that associations between $25(\mathrm{OH}) \mathrm{D}$ and chronic diseases, if they do exist, are non-linear. For example, in a meta-analysis, risk of cardiovascular disease decreased with increasing $25(\mathrm{OH})$ D concentration up to $60 \mathrm{nmol} / \mathrm{L}$, above which there was no further decrease or increase [47]. In a randomized controlled trial of community-dwelling women aged 70 years or older, annual oral administration of highdose cholecalciferol (vitamin $\mathrm{D}_{3}$ ) resulted in an increased risk of falls and fractures [48]. Taken together, these data highlight the need for further research to determine the optimal $25(\mathrm{OH}) \mathrm{D}$ concentrations for preventing fractures in different populations and reducing the risk of other chronic diseases.

\section{Conclusions}

This study confirms our previous results that greater circulating $25(\mathrm{OH}) \mathrm{D}$ concentrations were associated with an increased risk of total hip replacement for OA in men but not in women. Further work is needed to understand the mechanisms underlying these findings. Our findings also highlight the need to determine the optimal levels of circulating $25(\mathrm{OH}) \mathrm{D}$ in order to reduce the risk of chronic diseases such as hip OA.

\begin{abstract}
Abbreviations
25(OH)D: 25-hydroxyvitamin D; OR: Odds ratios; Cl: Confidence intervals; OA: Osteoarthritis; MCCS: Melbourne Collaborative Cohort Study; AOA NJRR: Australian Orthopaedic Association National Joint Replacement Registry; SEIFA: Socio-Economic Indexes For Areas; BMI: Body mass index; LC-MS/MS: Liquid chromatography-tandem mass spectrometry; NIST: National Institute of Standards and Technology; DEQAS: Vitamin D External Quality Assessment Scheme; HR: Hazard ratio.
\end{abstract}

\section{Acknowledgements}

The Melbourne Collaborative Cohort Study was made possible by the contribution of many people, including the original investigators and the diligent team who recruited the participants and who continue working on follow up. We would like to express our gratitude to the many thousands of Melbourne residents who participated in the study. For the data linkage, we would especially like to thank the Registry coordinator Ann Tomkins and statistician Lisa Miller from the Australian Orthopaedic Association National Joint Replacement Registry, and Ms. Georgina Marr from Cancer Council Victoria.

\section{Authors' contributions}

GGG and DRE were involved in the initial design of this cohort study and the data collection. GGG, DRE, DWE, AKH, EJW were involved in the design of the vitamin D case cohort study. GGG, FMC, YW, AEW and SEG were involved in linking the MCCS cohort with the AOA NJRR. SMH, YW and FMC were involved in the conception and design of the paper. SMH wrote the first and final draft of the paper with input from YW, AKH, GGG, DRE, DWE, EJW, SEG, AEW and FMC. FMC, AKH, DRE, EJW and YW provided input on the data analysis, all the drafts, and the final paper. SMH did the statistical analysis. YW, AKH, GGG, DRE, DWE, EJW, AEW and FMC interpreted the data, and reviewed and commented on all drafts and the final paper. The author(s) read and approved the final manuscript.

\section{Funding}

The recruitment of the Melbourne Collaborative Cohort Study was supported by funding from VicHealth and Cancer Council Victoria. This study was further supported by Australian National Health and Medical Research Council (NHMRC) grants 209057, 251553, and 504711, and by infrastructure provided by Cancer Council Victoria. The vitamin D study was supported by the Australian National Health and Medical Research Council (NHMRC) grant 623208. SMH is the recipient of NHMRC Early Career Fellowship (\#1142198). YW is the recipient of NHMRC Translating Research into Practice Fellowship (APP1 168185). AEW is the recipient of the Royal Australian College of Physician Fellows Career Development Fellowship. The funding sources had no role in the design, conduct, or reporting of the study or the decision to submit the manuscript for publication.

\section{Availability of data and materials}

The datasets used and/or analysed during the current study are available from the corresponding author on reasonable request.

\section{Declarations}

\section{Ethics approval and consent to participate}

The MCCS study protocol was approved by the Cancer Council Victoria Human Research Ethics Committee (IEC No. 9001). The data linkage study (between MCCS and AOA NJRR) protocol was approved by the Human Research Ethics Committees of Cancer Council Victoria (HREC 0601), and Monash University (2006000608). Participants gave written informed consent to participate and for the investigators to obtain access to their medical records. 


\section{Consent for publication \\ Not applicable.}

\section{Competing interests}

The authors declare that they have no competing interests.

\begin{abstract}
Author details
${ }^{1}$ Department of Epidemiology and Preventive Medicine, School of Public Health and Preventive Medicine, Monash University, 553 St Kilda Road, Melbourne, VIC 3004, Australia. ${ }^{2}$ Department of Epidemiology and Biostatistics, School of Public Health, Imperial College London, London W2 1PG, UK. ${ }^{3}$ Centre for Epidemiology and Biostatistics, Melbourne School of Population and Global Health, The University of Melbourne, Carlton, VIC 3053, Australia. ${ }^{4}$ Cancer Epidemiology Division, Cancer Council Victoria, Melbourne, VIC 3004, Australia. ${ }^{5}$ Queensland Brain Institute, The University of Queensland, Brisbane, QLD 4072, Australia. ${ }^{6}$ Queensland Centre for Mental Health Research, The Park Centre for Mental Health, Wacol, QLD 4076, Australia. ${ }^{7}$ Department of Medical Statistics, London School of Hygiene \& Tropical Medicine, London WC1E 7HT, UK. ${ }^{8}$ Department of Surgery, Flinders University, Bedford Park, SA 5042, Australia. ${ }^{9}$ Australian Orthopaedic Association National Joint Replacement Registry, Discipline of Public Health, School of Population Health \& Clinical Practice, University of Adelaide, Adelaide, SA 5005, Australia.
\end{abstract}

Received: 1 July 2021 Accepted: 1 October 2021

Published online: 19 October 2021

\section{References}

1. Murphy NJ, Eyles JP, Hunter DJ. Hip Osteoarthritis: Etiopathogenesis and Implications for Management. Adv Ther. 2016;33:1921-46.

2. Beswick AD, Wylde V, Gooberman-Hill R, Blom A, Dieppe P. What proportion of patients report long-term pain after total hip or knee replacement for osteoarthritis? A systematic review of prospective studies in unselected patients. BMJ Open. 2012;2:e000435.

3. Gregory JS, Waarsing JH, Day J, Pols HA, Reijman M, Weinans H, et al. Early identification of radiographic osteoarthritis of the hip using an active shape model to quantify changes in bone morphometric features: can hip shape tell us anything about the progression of osteoarthritis? Arthritis Rheum. 2007;56:3634-43.

4. Hill TR, Aspray TJ. The role of vitamin D in maintaining bone health in older people. Ther Adv Musculoskelet Dis. 2017;9:89-95.

5. Holick MF. Vitamin D status: measurement, interpretation, and clinical application. Ann Epidemiol. 2009;19:73-8.

6. Lane NE, Gore LR, Cummings SR, Hochberg MC, Scott JC, Williams EN, et al. Serum vitamin D levels and incident changes of radiographic hip osteoarthritis: a longitudinal study. Study of Osteoporotic Fractures Research Group. Arthritis Rheum. 1999;42:854-60.

7. Chaganti RK, Parimi N, Cawthon P, Dam TL, Nevitt MC, Lane NE. Association of 25-hydroxyvitamin D with prevalent osteoarthritis of the hip in elderly men: the osteoporotic fractures in men study. Arthritis Rheum. 2010;62:511-4.

8. Hussain SM, Daly RM, Wang Y, Shaw JE, Magliano DJ, Graves S, et al. Association between serum concentration of 25-hydroxyvitamin D and the risk of hip arthroplasty for osteoarthritis: result from a prospective cohort study. Osteoarthr Cartil. 2015;23:2134-40.

9. Konstari $S$, Kaila-Kangas $L$, Jaaskelainen T, Heliovaara M, Rissanen $H$, Marniemi J, et al. Serum 25-hydroxyvitamin D and the risk of knee and hip osteoarthritis leading to hospitalization: a cohort study of 5274 Finns. Rheumatology (Oxford). 2014;53:1778-82.

10. Konstari S, Paananen M, Heliovaara M, Knekt P, Marniemi J, Impivaara $\mathrm{O}$, et al. Association of 25-hydroxyvitamin $\mathrm{D}$ with the incidence of knee and hip osteoarthritis: a 22-year follow-up study. Scand J Rheumatol. 2012;41:124-31.

11. Fox KM, Cummings SR, Powell-Threets K, Stone K. Family history and risk of osteoporotic fracture. Study of Osteoporotic Fractures Research Group. Osteoporos Int. 1998;8:557-62.

12. Orwoll E, Blank JB, Barrett-Connor E, Cauley J, Cummings S, Ensrud K, et al. Design and baseline characteristics of the osteoporotic fractures in men
(MrOS) study--a large observational study of the determinants of fracture in older men. Contemp Clin Trials. 2005;26:569-85.

13. Milne RL, Fletcher AS, Maclnnis RJ, Hodge AM, Hopkins AH, Bassett JK, et al. Cohort Profile: The Melbourne Collaborative Cohort Study (Health 2020). Int J Epidemiol. 2017:46:1757-1757i.

14. Giles GG, English DR. The Melbourne Collaborative Cohort Study. IARC Sci Publ. 2002;156:69-70.

15. Australian Orthopaedic Association National Joint Replacement Registry. Annual Report. Adelaide: AOA; 2018

16. Maclnnis RJ, English DR, Hopper JL, Haydon AM, Gertig DM, Giles GG. Body size and composition and colon cancer risk in men. Cancer Epidemiol Biomark Prev. 2004;13:553-9.

17. Jayasekara H, English DR, Haydon A, Hodge AM, Lynch BM, Rosty C, et al. Associations of alcohol intake, smoking, physical activity and obesity with survival following colorectal cancer diagnosis by stage, anatomic site and tumor molecular subtype. Int J Cancer. 2018;142:238-50.

18. Ainsworth BE, Haskell WL, Leon AS, Jacobs DR Jr, Montoye HJ, Sallis JF, et al. Compendium of physical activities: classification of energy costs of human physical activities. Med Sci Sports Exerc. 1993;25:71-80.

19. Heath AK, Williamson EJ, Ebeling PR, Kvaskoff D, Eyles DW, English DR. Measurements of 25-hydroxyvitamin D concentrations in archived dried blood spots are reliable and accurately reflect those in plasma. J Clin Endocrinol Metab. 2014;99:3319-24.

20. Eyles D, Anderson C, Ko P, Jones A, Thomas A, Burne T, et al. A sensitive $\mathrm{LC} / \mathrm{MS} / \mathrm{MS}$ assay of $25 \mathrm{OH}$ vitamin D3 and $25 \mathrm{OH}$ vitamin D2 in dried blood spots. Clin Chim Acta. 2009;403:145-51.

21. Heath AK, Williamson EJ, Hodge AM, Ebeling PR, Eyles DW, Kvaskoff D, et al. Vitamin D status and the risk of type 2 diabetes: The Melbourne Collaborative Cohort Study. Diabetes Res Clin Pract. 2019;149:179-87.

22. Hussain SM, Cicuttini FM, Bell RJ, Robinson PJ, Davis SR, Giles GG, et al. Incidence of total knee and hip replacement due to osteoarthritis in relation to circulating sex steroid hormone concentrations in women. Arthritis Rheum. 2014;66:2144-51.

23. Bouillon R, Van Schoor NM, Gielen E, Boonen S, Mathieu C, Vanderschueren D, et al. Optimal vitamin D status: a critical analysis on the basis of evidence-based medicine. J Clin Endocrinol Metab. 2013;98:E1283-304.

24. Cranney A, Horsley T, O'Donnell S, Weiler H, Puil L, Ooi D, et al. Effectiveness and safety of vitamin $D$ in relation to bone health. Evid Rep Technol Assess (Full Rep). 2007:1-235.

25. Doherty M, Courtney P, Doherty S, Jenkins W, Maciewicz RA, Muir K, et al. Nonspherical femoral head shape (pistol grip deformity), neck shaft angle, and risk of hip osteoarthritis: a case-control study. Arthritis Rheum. 2008;58:3172-82.

26. Hardcastle SA, Dieppe P, Gregson CL, Hunter D, Thomas GE, Arden NK, et al. Prevalence of radiographic hip osteoarthritis is increased in high bone mass. Osteoarthr Cartil. 2014:22:1120-8.

27. Cauley JA. Estrogen and bone health in men and women. Steroids. 2015:99:11-5.

28. Hofer D, Munzker J, Schwetz V, Ulbing M, Hutz K, Stiegler P, et al. Testicular synthesis and vitamin D action. J Clin Endocrinol Metab. 2014;99:3766-73

29. Kuhr DL, Sjaarda LA, Alkhalaf Z, Omosigho UR, Connell MT, Silver RM, et al. Vitamin $D$ is associated with bioavailability of androgens in eumenorrheic women with prior pregnancy loss. Am J Obstet Gynecol. 2018;218:608. e601-6.

30. Lim JS, Kim KM, Rhee Y, Lim SK. Gender-dependent skeletal effects of vitamin D deficiency in a younger generation. J Clin Endocrinol Metab. 2012;97:1995-2004.

31. Hussain SM, Cicuttini FM, Giles GG, Graves SE, Wang Y. Relationship between circulating sex steroid hormone concentrations and incidence of total knee and hip arthroplasty due to osteoarthritis in men. Osteoarthr Cartil. 2016;24:1408-12.

32. Durup D, Jorgensen HL, Christensen J, Tjonneland A, Olsen A, Halkjaer J, et al. A Reverse J-Shaped Association Between Serum 25-Hydroxyvitamin D and Cardiovascular Disease Mortality: The CopD Study. J Clin Endocrinol Metab. 2015;100:2339-46.

33. McGrath JJ, Eyles DW, Pedersen CB, Anderson C, Ko P, Burne TH, et al. Neonatal vitamin D status and risk of schizophrenia: a population-based case-control study. Arch Gen Psychiatry. 2010;67:889-94. 
34. Zittermann A, lodice S, Pilz S, Grant WB, Bagnardi V, Gandini S. Vitamin D deficiency and mortality risk in the general population: a meta-analysis of prospective cohort studies. Am J Clin Nutr. 2012;95:91-100.

35. Lauridsen AL, Vestergaard P, Hermann AP, Brot C, Heickendorff $L$, Mosekilde $L$, et al. Plasma concentrations of 25-hydroxy-vitamin D and 1,25-dihydroxy-vitamin D are related to the phenotype of Gc (vitamin D-binding protein): a cross-sectional study on 595 early postmenopausal women. Calcif Tissue Int. 2005;77:15-22.

36. Hofmann JN, Yu K, Horst RL, Hayes RB, Purdue MP. Long-term variation in serum 25-hydroxyvitamin D concentration among participants in the Prostate, Lung, Colorectal, and Ovarian Cancer Screening Trial. Cancer Epidemiol Biomark Prev. 2010;19:927-31.

37. Sonderman JS, Munro HM, Blot WJ, Signorello LB. Reproducibility of serum 25-hydroxyvitamin d and vitamin D-binding protein levels over time in a prospective cohort study of black and white adults. Am J Epidemiol. 2012;176:615-21.

38. Jorde R, Sneve M, Hutchinson M, Emaus N, Figenschau Y, Grimnes G. Tracking of serum 25-hydroxyvitamin $D$ levels during 14 years in a population-based study and during 12 months in an intervention study. Am J Epidemiol. 2010;171:903-8.

39. Touvier M, Deschasaux M, Montourcy M, Sutton A, Charnaux N, Kesse-

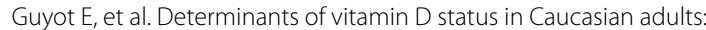
influence of sun exposure, dietary intake, sociodemographic, lifestyle, anthropometric, and genetic factors. J Invest Dermatol. 2015;135:378-88.

40. Freedman DM, Cahoon EK, Rajaraman P, Major JM, Doody MM, Alexander $\mathrm{BH}$, et al. Sunlight and other determinants of circulating 25-hydroxyvitamin D levels in black and white participants in a nationwide U.S. study. Am J Epidemiol. 2013;177:180-92.
41. Helde-Frankling M, Björkhem-Bergman L. Vitamin D in Pain Management. Int J Mol Sci. 2017;18:2170.

42. Vestergaard P, Hermann P, Jensen JE, Eiken P, Mosekilde L. Effects of paracetamol, non-steroidal anti-inflammatory drugs, acetylsalicylic acid, and opioids on bone mineral density and risk of fracture: results of the Danish Osteoporosis Prevention Study (DOPS). Osteoporos Int. 2012;23:1255-65.

43. Mondul AM, Weinstein SJ, Layne TM, Albanes D. Vitamin D and Cancer Risk and Mortality: State of the Science, Gaps, and Challenges. Epidemiol Rev. 2017:39:28-48

44. Dawson-Hughes B, Heaney RP, Holick MF, Lips P, Meunier PJ, Vieth R. Estimates of optimal vitamin D status. Osteoporos Int. 2005;16:713-6.

45. Malabanan A, Veronikis IE, Holick MF. Redefining vitamin D insufficiency. Lancet. 1998:351:805-6.

46. Holick MF. Vitamin D deficiency. N Engl J Med. 2007;357:266-81.

47. Wang L, Song Y, Manson JE, Pilz S, März W, Michaëlsson K, et al. Circulating 25-hydroxy-vitamin D and risk of cardiovascular disease: a meta-analysis of prospective studies. Circ Cardiovasc Qual Outcomes. 2012;5:819-29.

48. Sanders KM, Stuart AL, Williamson EJ, Simpson JA, Kotowicz MA, Young $D$, et al. Annual high-dose oral vitamin $D$ and falls and fractures in older women: a randomized controlled trial. Jama. 2010;303:1815-22.

\section{Publisher's Note}

Springer Nature remains neutral with regard to jurisdictional claims in published maps and institutional affiliations.
Ready to submit your research? Choose BMC and benefit from:

- fast, convenient online submission

- thorough peer review by experienced researchers in your field

- rapid publication on acceptance

- support for research data, including large and complex data types

- gold Open Access which fosters wider collaboration and increased citations

- maximum visibility for your research: over $100 \mathrm{M}$ website views per year

At BMC, research is always in progress.

Learn more biomedcentral.com/submissions 